\title{
Using the Myers-Briggs Type Indicator (MBTI) for modeling multiagent systems
}

\author{
Uso do Myers-Briggs Type Indicator (MBTI) para modelagem de sistemas multiagentes
}

\author{
Luiz Fernando Braz ${ }^{1}$, Jaime Simão Sichman ${ }^{1}$
}

\begin{abstract}
:
The formation of high-performance teams has been a constant challenge for organizations, which despite considering human capital as one of the most important resources, it still lacks the means to allow them to have a better understanding of several factors that influence the formation of these teams. In this sense, studies also demonstrate that teamwork has a significant impact on the results presented by organizations, in which human behavior is highlighted as one of the main aspects to be considered in the building of work teams. The Myers-Briggs Type Indicator seeks to classify the behavioral preferences of individuals around eight characteristics, which grouped as dichotomies, describe different psychological types. With it, researchers have sought to expand the ability to understand the human factor, using strategies with multiagent systems that, through experiments and simulations, using computer resources, enable the development of artificial agents that simulate human actions. In this work, we present an overview of the research approaches that use MBTI to model agents, aiming at providing a better knowledge of human behavior. Additionally, we make a preliminary discussion of how these results could be explored in order to advance the studies of psychological factors' influence in organizations' work teams formation.
\end{abstract}

Keywords: Multiagent systems - MAS - High-Performance Teams - MBTI

\section{Resumo:}

A formação de equipes de alta performance tem sido um desafio constante para as organizações, que apesar de considerarem o capital humano um dos recursos mais importantes, ainda carecem de meios que lhes permitam compreender melhor os diversos fatores que influenciam a formação destas equipes. Nesse sentido, estudos também demonstram que o trabalho em equipe tem impacto significativo nos resultados apresentados pelas organizações, em que o comportamento humano é destacado como um dos principais aspectos a serem considerados na formação das equipes de trabalho. O Myers-Briggs Type Indicator busca classificar as preferências comportamentais dos indivíduos em torno de oito características, que agrupadas em dicotomias, descrevem diferentes tipos psicológicos. Com ele, pesquisadores têm buscado ampliar a capacidade de compreensão do fator humano, utilizando estratégias com o uso de sistemas multiagentes que, por meio de experimentos e simulações, utilizando recursos computacionais, possibilitam o desenvolvimento de agentes artificiais que simulam ações humanas. Neste trabalho, apresenta-se um panorama das pesquisas que utilizam o MBTI para modelar agentes, com o objetivo de fornecer uma melhor compreensão do comportamento humano. Adicionalmente, apresenta-se uma discussão preliminar de como tais resultados poderiam ser explorados para avançar o estudo da influência de fatores psicológicos na formação de equipes de trabalho nas organizações.

Palavras-Chave: Sistemas Multiagentes - SMA — Times de Alto Desempenho - MBTI

${ }^{1}$ Laboratório de Técnicas Inteligentes (LTI), Escola Politécnica (EP), Universidade de São Paulo (USP), Av. Prof. Luciano Gualberto 158 trav. 3 , 05508-970, São Paulo - São Paulo, Brasil

*Corresponding author: luiz.braz@usp.br

DOI: http://dx.doi.org/10.22456/2175-2745.110015 • Received: 18/12/2020 • Accepted: 07/08/2021

CC BY-NC-ND 4.0 - This work is licensed under a Creative Commons Attribution-NonCommercial-NoDerivatives 4.0 International License.

\section{Introduction}

In order to better understand human behavior, several studies have been carried out over the years seeking to identify patterns that allow certain behavioral aspects to be categorized into similarity groups [1]. With the founding of the fatigue studies laboratory by Luigi Patrizi in 1889, which 
sought to investigate psychophysiological aspects associated with fatigue, and later with the emergence of a new area of Psychology called Work Psychology, the study of behavior in organizations has been subject to constant analysis. Inspired by Frederick Winslow Taylor's ideas about work production and organization, Frank and Lillian Gilbreth developed the socalled "time and motion study" in which, seeking to maximize efficiency and performance at work, they studied how the personal characteristics of workers could influence productivity [2]. In 1903, William Stern coined the term "psychotechnics" [3] and with Hugo Münsterberg's publication entitled "Psychology and Industrial Efficiency" in 1913, psychological experiments conducted in the laboratory were carried out to study and demonstrate how psychology could support means more effective in the selection process [1]. It is also possible to observe that Münsterberg's proximity to Taylor's ideas demonstrates how both were integrated into the same set of concerns related to the world of work [2].

In [4], the author mentions that mainly during the decades between the two world wars, organizational psychology has expanded to several areas, evolving together with organizations and specializing in different problems brought by industrialization, among them the study of how human behavior could influence the productivity in the organizations. Several techniques and processes have been developed since then, aiming to improve the efficiency of organizations. For example, the selective processes begin to have employees more aligned with their business needs, thus providing more significant business value generation. Some other factors have also strongly influenced the recruitment and selection process in the face of the demand for a new worker profile. These factors include, for example, the companies search for individuals who are more resilient to the changes and adapted to work in adverse situations [5] and have brought significant innovation in the selection process, expanding the use of techniques to assess technical, interpersonal, and behavioral skills of employees.

Inspired by Carl Jung's theory of psychological types, Katherine Briggs and Isabel Myers developed the MyersBriggs Type Indicator (MBTI), which is currently one of the most used instruments to classify people's behavioral characteristics and preferences. The instrument initially developed with the primary objective of allowing people to understand better their characteristics and preferences [6], was later expanded and used in different areas such as for the improvement of educational methods adapted to students' personality characteristics [7], for studies of leadership behaviors [8] and for recruiting and selecting people [9], in addition to others.

It is possible to distinguish and categorize through socalled dichotomies sixteen distinct groups with similarity patterns in terms of behavioral preferences and thus understand particularities that certain groups may need for different applications. MBTI allows individuals to be classified according to their behavioral preferences considering different aspects grouped as dichotomies: Extraversion or Introversion, Sensing or Intuition, Thinking or Feeling, and Judging or Perceiving, classifying each person in one of the sixteen possible combinations of behavioral preferences. In this way, it is possible to observe in individuals characteristics that indicate how they observe the world around them and how they make decisions influenced by these characteristics [6].

In this work, we seek to study how the personality of individuals can influence their productivity in an organizational context. For that purpose, scientific studies focusing on multiagent systems (MAS) will be analyzed. MAS aim to "study generic models from which agents, organizations and interactions can be conceived" [10] as the means for agents to cooperate in solving a specific problem. MAS also offer powerful tools to deal with abstract situations and with a high level of complexity [11], ideal for a deeper analysis of how people, with their complex interpersonal relationships, interact with others to perform tasks with a common goal. In this way, it will be possible to analyze how agents modeled with different psychological types derived from MBTI could perform specific tasks individually and in teams.

In particular, the present work is restricted to a review of previous studies regarding the use of MBTI for modeling multiagent systems and briefly discusses some possible adaptations needed to be used in more complex simulations involving the formation of high-performance teams.

This paper is organized as follows: Section 2 presents the theoretical basis of MBTI (Myers-Briggs Type Indicator), exploring some basic concepts, and describing each of the dichotomies proposed in the instrument. Section 3 discusses how MBTI can be used in organizations considering different types of approaches. The most common types of use, benefits, misuses, and limitations of MBTI are also analyzed regarding its application in different contexts. Section 4 analyzes how multiagent systems could assist in the simulation of human behavior using computational resources. BDI (Belief-DesireIntention) architecture is also explored to enhance its use by expanding with emotional capabilities. Section 5 addresses how research has been conducted in modeling MAS using a framework with MBTI as a base. We indicate some preliminary direction to extend this work for a more complex analysis on teams formation in section 6. Finally, Section 7 presents our conclusions and future work.

\section{Myers-Briggs Type Indicator - MBTI}

MBTI (Myers Briggs Type Indicator), initially developed in 1942 by Isabel Myers and her mother Katherine Briggs and inspired by Carl Jung's theory of psychological types, seeks to ensure the theoretical foundations that Jung envisaged can be applied in people's lives, bringing a clearer picture of how the different human behaviors influenced by the distinct psychological types of each individual can be better studied and understood. It is an instrument that seeks to address two main issues: Identify the behavioral preferences of individuals following four proposed dichotomies, either implicitly or explicitly by Jung, and identify and describe the sixteen different types of personalities that result from interactions around 
these preferences [6]. With this, MBTI proposes typological classifications, called dichotomies, which aim to identify these behavioral preferences, categorizing the common preferences of the human being and allowing different approaches to be applied through the results of these studies to have a better picture of the behaviors despite the complexity of people.

In this way, the following dichotomies are presented: Extraversion and Introversion (E-I), Sensing and Intuition (S-N), Thinking and Feeling (T-F), and Judging and Perceiving (J-P), following opposite orientations regarding the preferences of each individual. An important aspect to note is that these preferences do not indicate, for example, that an individual is more extraverted than another, not representing she or he is extraverted all the time [1], but that each has a greater preference for extraversion, with a tendency to be more sociable and expressive [6] than introverted individuals. Therefore, this does not mean that an individual, even identified as extraverted, cannot at times present characteristics more associated with introverted individuals, for example.

In the following sections, the dichotomies cited will be analyzed, exploring how each of them can influence the behavior of individuals, directing their actions according to their preferences.

\subsection{Extraversion-Introversion (E-I)}

The Extraversion-Introversion dichotomy seeks to explain how individuals tend to direct their energies through interaction with the external or internal world. Much of the theory developed by Jung was devoted to concepts aimed at these two attitudes or orientations [1][6][12] exploring how people tend to guide their actions. Individuals with a preference for extraversion seek to be sociable, communicating through speech, learning from other individuals, and leading well with proactivity [13]. An individual with an extraverted attitude experiences a desire to act on the environment, to affirm its importance, and to increase its effect. They generally also tend to be action-oriented and open to new experiences [6]. In contrast, individuals with a preference for introversion seek privacy, preferring to communicate through other means, such as writing, learning individually, and being proactive only when necessary [13]. "In the Introverted attitude, energy is drawn from the environment toward inner experience and reflection" [6] in that people with this preference usually develop some characteristics related to introversion like enjoyment for privacy and for being alone and the desire to "think things out" before talking about them [6] [13].

\subsection{Sensing-Intuition (S-N)}

The Sensing-Intuition (S-N) dichotomy describes how individuals prefer to seek information from the world around them [6][12], that is, how people with different psychological types prefer to interact with things and people, either through sensory mechanisms or using their intuition [1]. Individuals with a preference for Sensing "like to take information that is real and tangible" [12], basically focusing on something that is concrete and that can represent a short-term gain. These individuals tend to observe facts or happenings through one or more of the five senses. Individuals with a preference for intuition use more abstract perceptions to interact with the world. It gives them a better understanding of patterns and interrelationships that can bring meaning to their perceptions, this being a less obvious process and more subject to a subjective understanding of the world [6].

\subsection{Thinking-Feeling (T-F)}

This dichotomy describes how individuals make decisions [1][6][12][13] in which two opposite preferences are placed: thinking and feeling. Individuals with a preference for thinking seek through logical analyzes focused on objective factors [1] to act more rationally and logically, making decisions impersonally and basing these decisions by measuring the consequences that may result from these decisions taken. On the other hand, feelings individuals seek to make their decisions based on personal or social values [6]. It can also be seen that "a feeling person makes decisions by considering what is important to themselves and the people around them" [13]. The harmony of the environment is something essential for these people, analyzing how their own decisions can affect the goals of other people, anticipating any adverse effects that may cause to others [6].

\subsection{Judging-Perceiveing (J-P)}

The fourth dichotomy, Judging and Perceiving, seeks to describe how individuals deal with the outside world, whether in an organized and systematic way of life or through more dynamic and spontaneous actions [12]. This dichotomy was not explicitly mentioned in the theory of Jung [6] and is one of the main changes brought about by MBTI. Individuals with a judging preference seek an orderly way to deal with the world, in which they like to make decisions that were strictly planned, with well-defined plans and strategies to be followed [13]. They tend to be organized and like to have things settled, planning their paths methodically and systematically to achieve the planned objectives [12]. Perceiving individuals prefer to use their senses or intuition when dealing with the outside world [1][6], making them more flexible in the plans initially drawn. These individuals "prefer to be spontaneous, seeking ways to experience and understand life and the world around them, not control it" [13]. Perceiving individuals prefer to stay open to last-minute options to be able to get new information and ideas that may arise, making them able to adapt according to the circumstances that arise [12].

\subsection{Personality types}

The dichotomies are consolidated according to their distinct particularities. It is possible to see in Table 1 (adapted from [12]) the characteristics of each one, and also the differences between them. In [12], according to the author, "Psychological type and MBTI instrument provide a rational structure for understanding normal, everyday differences between people" providing a constructive learning experience in which people can more effectively understand behavioral differences and 
Table 1. The characteristics of the personality types (adapted from [12])

\begin{tabular}{|c|c|c|}
\hline Dichotomy & Personality Type & Characteristics \\
\hline \multirow{6}{*}{ E-I } & \multirow{6}{*}{ Extraversion } & Attuned to external environment \\
\hline & & Prefer to communicate by talking \\
\hline & & Work out ideas by talking them through \\
\hline & & Learn best through doing or discussing \\
\hline & & Sociable and expressive \\
\hline & & Readily take initiative in work and relationships \\
\hline \multirow{6}{*}{ E-I } & \multirow{6}{*}{ Introversion } & Drawn to their inner world \\
\hline & & Prefer to communicate in writing \\
\hline & & Work out ideas by reflecting on them \\
\hline & & Learn best by reflection, mental "practice" \\
\hline & & Private and contained \\
\hline & & Take initiative when the situation or issue is very important to them \\
\hline \multirow{7}{*}{$\mathrm{S}-\mathrm{N}$} & \multirow{7}{*}{ Sensing } & Oriented to present realities \\
\hline & & Factual and concrete \\
\hline & & Focus on what is real and actual \\
\hline & & Observe and remember specifics \\
\hline & & Build carefully and thoroughly toward conclusions \\
\hline & & Understand ideas and theories through practical applications \\
\hline & & Trust experience \\
\hline \multirow{7}{*}{$\mathrm{S}-\mathrm{N}$} & \multirow{7}{*}{ Intuition } & Oriented to future possibilities \\
\hline & & Imaginative and verbally creative \\
\hline & & Focus on the patterns and meanings in data \\
\hline & & Remember specifics when they relate to a pattern \\
\hline & & Move quickly to conclusions, follow hunches \\
\hline & & Want to clarify ideas and theories before putting them into practice \\
\hline & & Trust inspiration \\
\hline \multirow{7}{*}{ T-F } & \multirow{7}{*}{ Thinking } & Analytical \\
\hline & & Use cause-and-effect reasoning \\
\hline & & Solve problems with logic \\
\hline & & Strive for an objective standard of truth \\
\hline & & Reasonable \\
\hline & & Can be "tough-minded" \\
\hline & & Fair-want everyone treated equally \\
\hline \multirow{7}{*}{ T-F } & \multirow{7}{*}{ Feeling } & Empathetic \\
\hline & & Guided by personal values \\
\hline & & Assess impacts of decisions on People \\
\hline & & Strive for harmony and positive interactions \\
\hline & & Compassionate \\
\hline & & May appear "tenderhearted" \\
\hline & & Fair-want everyone treated as an individual \\
\hline \multirow{7}{*}{$\mathrm{J}-\mathrm{P}$} & \multirow{7}{*}{ Judging } & Scheduled (have well-defined schedules) \\
\hline & & Organize their lives \\
\hline & & Systematic \\
\hline & & Methodical \\
\hline & & Make short- and long-term plans \\
\hline & & Like to have things decided \\
\hline & & Try to avoid last-minute stresses \\
\hline \multirow{7}{*}{$\mathrm{J}-\mathrm{P}$} & \multirow{7}{*}{ Perceiving } & Spontaneous \\
\hline & & Flexible \\
\hline & & Casual \\
\hline & & Open-ended \\
\hline & & Adapt, change course \\
\hline & & Like things loose and open to change \\
\hline & & Feel energized by last-minute pressures \\
\hline
\end{tabular}


Table 2. The personality types (adapted from [1][13])

\begin{tabular}{llcccc}
\hline & & \multicolumn{2}{c}{ Sensing (S) } & \multicolumn{2}{c}{ iNtuition (N) } \\
\hline \multirow{4}{*}{ Introverted (I) } & & Thinking (T) & Feeling (F) & Thinking (T) & Feeling (F) \\
& Judging (J) & ISTJ & ISFJ & INTJ & INFJ \\
\cline { 2 - 6 } Extraverted (E) & Perceiving (P) & ISTP & ISFP & INTP & INFP \\
\cline { 2 - 6 } & Perceiving (P) & ESTJ & ESFJ & ENTJ & ENFJ \\
\hline
\end{tabular}

perhaps they can better deal with their own internal bias, having a broader understanding of opposing psychological types of other and better developing acceptance of what is different from your own belief. Individuals' behavioral preferences can then be categorized following the combination for each preference of the four dichotomies demonstrated $\left(4^{2}=16\right)$. Thus, sixteen distinct types are formed from these preferences, thus forming a unique personality type for each individual [6]. All these combinations can be also seen in the Table 2 (adapted from [1][13]).

\section{Using $\mathrm{MBTI}$ in Organizations}

Thousands of organizations have widely used MBTI over the years [6] [14], its vast study material allows its dissemination to the most varied fields, such as education, for example, to study the different learning styles [7] [15], as well as to study the different types of interpersonal relationships [12] between individuals. This section explores its use in an organizational context, analyzing how the instrument may help companies improving their understanding of human behavior in different work situations.

\subsection{Common uses}

Due to the multidisciplinary nature of MBTI, different applications of the instrument can be observed in organizations, [12] mentions some common organizational cases, such as: improving communication, better dealing with conflict situations, enhancing problem-solving and decision making, better managing stress aspects, among others. Despite not being an instrument for measuring skills or abilities MBTI can provide important insights for example, to better understand what would be the best environment for an employee given their behavioral preferences, imagining that in this way it can contribute to a better performance of the worker [14].

The authors also add other applications of MBTI in an organizational context such as team building, improving customer service, reconciling group differences, career planning, adapting to change, and others. Its use can contribute so that these different situations are better managed with prior knowledge of the psychological aspects involved. MBTI allows a more positive attitude in the relationship of companies and customers. It allows negotiations involving both parties to take place more effectively since aspects that generally raise more significant concerns in the customer-company relationship can be better addressed and developed with an understand- ing of the psychological factors of the individuals involved in these negotiations [12]. Finally, a study on the formation of multifunctional teams was carried out using MBTI to analyze specific behavioral characteristics of the members of a team. According to the study, personality differences can affect individual, and group performance in a work context, in which correctly identifying certain personalities of individuals is essential so that, for example, managers can act more effectively in improving the work team's performance. MBTI has been widely used for applications related to team building in organizations, given its usefulness in describing the preferences of individuals and correlating them with factors related to decision making and problem-solving [16].

\subsection{Benefits}

With the application of MBTI in a work context, several benefits can be obtained directly and indirectly by organizations "People tend to be attracted to, and have the most satisfaction in, careers that provide them with opportunities to express and use their psychological type preferences" [12]. It can be seen that individuals who work in environments with greater adherence to their psychological types are more likely to naturally be more efficient since they feel more motivated and energized by the environment in which they find themselves.

It is also noted that a good adaptation of the work environment following the different psychological types of people can provide greater effectiveness of the activities developed by employees as well as greater job satisfaction [6]. The authors still mention differences in some aspects, for example, comparing extraverted and introverted individuals in terms of the variety of jobs performed, the need for more dynamic activities, and the specific needs for communication for both psychological types. A clearer picture and prior identification of the needs and particularities of each one can enable organizations to adapt to their specific needs obtaining benefits that can result in more productive employees. They also add that MBTI provides data that can be used for a better knowledge of cultural aspects of the organization, supporting themes such as the diversity of work teams. Its constructive use can represent a significant advance for companies to build more diverse teams that respect each others' differences and work together.

Thus, the development of a greater capacity for understanding the differences between each member of the team can also result in greater clarity of how the work styles of each one can contain vulnerabilities that prevent work in harmony; consequently, the accomplishment of a common goal 
[12]. From a personality computing perspective, MBTI has also shown better comparative results with other models, such as the Big Five, in experiments related to Natural Language Processing in terms of performance. However, this last one still is more informative [17].

\subsection{Misuses and limitations}

Despite being a very popular instrument and widely used by thousands of companies, several studies have shown that MBTI must be applied with caution. Despite being considered a valuable tool in team building, MBTI can be misused, for example, to unjustly stereotype individuals in a work context [18]. As an example of its misuse for the selection of employees, the author mentions that the instrument is sometimes used to exclude people who do not have specific behavioral characteristics for a given job function. On the other hand, the author adds that the instrument can indeed be helpful as support for team building, in which the members of a team can, for example, learn to respect the differences between each other, facilitating that this process of understanding brings changes in the behavior of the relationship of the team members. Using MBTI as a support and not an exclusion tool can help companies create more harmonious teams respecting the different psychological types that exist. This present work seeks to study how the different personality types interact with each other, aiming at a common goal for the group, but without proposing or defining criteria for the selection or exclusion of any kind. The objective is to explore its use to understand the different behaviors of people (agents) individually and working in teams, understanding behavioral differences that can assist, for example, in the development of training, coaching, among others that can help the group's joint development.

Another important aspect that other studies have explored is related to the possible psychometric limitations of MBTI. In [19], it is mentioned that the instrument does not provide norms based on continuous scores and also raises doubts about its stability, citing examples in which the performance of test-retests demonstrated instabilities in the consequent results of the instrument. This topic regarding the reliability of MBTI (test-retest) is also discussed in [20] suggesting the need for further studies to be carried out at MBTI in order that its validation can be subjected to statistical techniques that guarantee greater trust regarding the validity of its results. It is also important to note that this work does not aim to validate MBTI as a psychometric instrument, based on the premise that the instrument can be useful as a tool to support the understanding of the different psychological types that exist in people and thus be able to observe the different behaviors derived from agents modeled after characteristics described in MBTI.

\section{Multiagent systems and simulation of behavior}

Each person has characteristics and particularities that make him or her a unique individual. The human being is not only intelligence but also emotion, and they have an essential function within a complex decision-making process that occurs in each individual all the time [21]. With its inherent complexities, the human being becomes the object of studies so that behaviors and characteristics can be represented through mechanisms that allow simulating the decision-making process.

In this context, approaches using techniques based on artificial intelligence have been increasingly used. The author mentions that, for example, the use of multiagent systems (MAS) "where each agent is an intelligent system that solves a specific problem" has helped to evolve the study of human behavior by enabling simulations of behaviors and interactions between agents who seek to represent people and problems of the real world. In [10], the authors cited that the objective of MAS field is to study "generic models from which agents, organizations, and interactions can be conceived ", aiming at the means for agents to cooperate in solving a specific problem that can contribute to improve the understanding, for example, of situations that involve people interactions in the organizations [1]. MAS should be aligned with multidisciplinary fields, in which areas such as social science, psychology, and cognitive science could be integrated and studied together, complementing each other and contributing to study human factors [21]. About this topic, logic-based [22] and cognitive sciences approaches have contributed significantly to the development of MAS [23] that have been increasingly used, allowing simulations involving numerous agents are computationally viable [24].

\subsection{Belief-Desire-Intention (BDI)}

Some theories in the MAS field have collaborated with the development of models that can support the development of autonomous agents who can act in a coordinated and cooperative way in order to carry out common tasks [23]. Amongst them, BDI (Belief-Desire-Intention) architecture has been playing an important role in representing the decision-making process of agents, supporting, for example, the modeling of agents for the simulation of human behavior [25]. BDI architecture can be used for practical reasoning in agents representing its beliefs, desires, and intentions [26], as presented in Figure 1. The authors explain that the agents' intentions are structured in plans, considering their beliefs about actions that may be useful in achieving objectives that may result in effects on certain conditions. In [25] the authors sum up that the BDI "is based upon a folk-psychological view of reasoning, that is, the way people think that they think," where it is able to provide a mechanism to increase the understanding of factors related to human reasoning and thus provide valuable techniques in simulating the decision-making process of individuals. Most of the systems that use BDI have a plan library that assists in the abstraction of specifications needed to achieve particular objectives or to carry out subtasks that guide them in carrying out the plan and consequently in reaching the proposed objective [27]. 


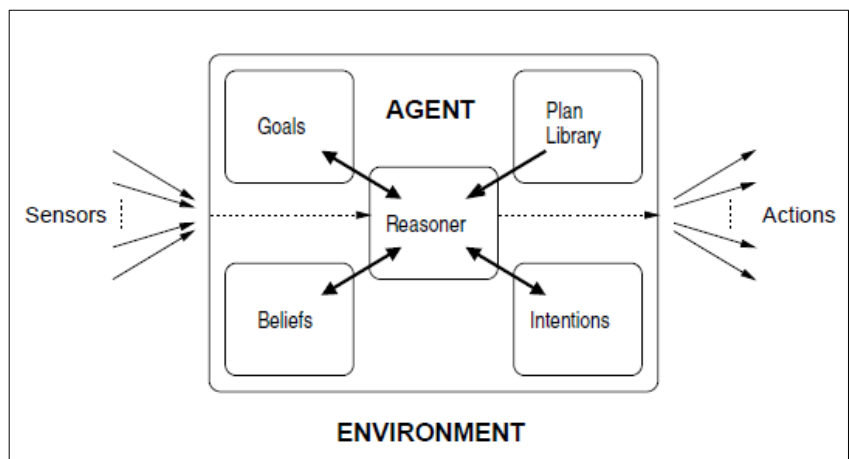

Figure 1. The key components of a BDI agent [25]

Each of the plans is associated with an event that can trigger actions necessary to achieve a particular objective. They also have a list of pre-conditions that describe the situation in which the particular plan can then be used, thus facilitating the mapping of processes to be used in the decision-making process, modeled according to different situations and problems [27].

\subsection{BDI Model}

In [28] an abstraction of the BDI architecture is proposed in order to represent dynamic structures that enable the representation of beliefs, desires, and intentions of the agents. It is explained that these structures are compressed together with a queue of events that also allow them to be updated from operations ensuring that the agents' mental state is actually fulfilled. In this architecture, it suggested an interpreter who represents these structures of events queue, beliefs, desires, and intentions:

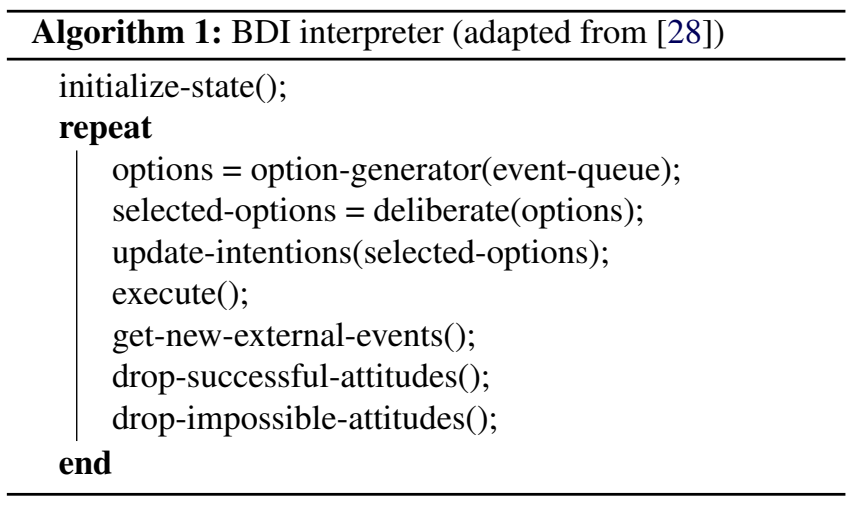

As detailed in Algorithm 1, for each execution cycle the interpreter performs the read of the event queue, thus defining a list of options that an agent can perform. Among them, a set of action options are selected, which can then, in fact, be adopted and updated in the agent's intention structure. If the agent has the proper intention, the action is then performed. Following the process, any new external events that arise during the execution of the cycle can also be added to the event queue after the execution of the actions, and at the end of the cycle, attitudes and desires that have been successful or that are impossible to achieve, are then dropped, and a new cycle can be started [28].

\subsection{Extending BDI with emotional capabilities}

Following the architecture proposed with BDI, some studies have sought to expand the theory by adding mechanisms that allow, for example, the representation of emotional aspects in agents, thus seeking to expand their ability to represent complex behaviors. Differently from personality traits that reflect people's characteristic patterns of thoughts, feelings, and behaviors [29], emotions reflect people's ability to subjectively experience certain states of the nervous system [30].

In [31] a conceptual architecture based on BDI is presented aiming to expand the classic architecture of the framework supporting the ability to represent artificial emotions in agents. The authors explain that these artificial emotions can be classified as metaphors of how a given emotional state could be modeled and represented in the agents through computational resources, making it possible for BDI to represent agents' actions and behaviors more reliable. Thus, emotions such as fear, joy, sadness, among others, can be artificially represented in agents using this architecture. As an example, an agent with the role of finding and extinguishing the fire can have perception functions activated given the presence of fire or smoke in its vision radius. Translating to the BDI architecture, its belief of the existence of fire will be updated, causing its fear-related emotional state to be impacted as well. Thus, an agent can decide the attitude to take, whether or not to try to attack the fire, given its desire and intention derived.

They still mention that the extension of the BDI can provide that agents can have the capacity to be self-aware, that is, allowing mechanisms to be implemented so that an agent can have an understanding of its own emotional state. About this aspect, an extension of the classical BDI model it is suggested in [27] so that additional capabilities can complement and enrich the modeling of agents with self-awareness, in which an agent could commit to a planned goal, only for example if it believes it has the capacity to achieve it in fact, directing their behavioral preferences following a rational logic that influences its behavior in the environment. The BDI extension described covers the use of capabilities in reasoning, which can provide a further advance in simulations of agents in heterogeneous environments where an agent can have information about other agents around it. This information can be shared with other agents aiming, for example, to perform common tasks. Several other complex situations can be derived from these interactions. For example, agents can influence other agents in the environment so that their desires and intentions can be realized.

In this sense, in [13] the extension of BDI is addressed by studying how it could add concepts related to the incorporation of personality to agents into the framework. They explore the use of MBTI theory as a basis for the development of structures capable of representing human personality in agents, defining functions that support the formulation of beliefs, de- 
sires, and intentions that may be associated with aspects of the sixteen different personalities types described in MBTI. These different personalities could then influence the agents' decision-making process and help to analyze how these behavioral characteristics can impact tasks in agents modeled with personalities based on MBTI. The extension of BDI can help understand how complex characteristics of human behavior can be better represented in the agents, developing aspects related to the demonstration of emotions, self-awareness, and personalities, thus enabling a better understanding of how these aspects can influence the decision-making process of agents.

\section{Modeling agents with MBTI}

In [13], the use of MBTI to model agents' personalities is studied in order to expand the scope of BDI to include the representation of the agents' behaviors following the psychological types described in the theory of human personality [1]. With this, several possibilities of applications can be better explored by observing how agents define plans, make decisions and interact with each other, influenced by their personalities. The approach allows the observation of behavioral aspects in the agents, modeled with different psychological types observed in different contexts. The authors analyze the achievement of a simple task (collecting food spread in an environment) by different agents (modeled with different personalities). With this environment, they can measure the performance of each one, both in homogeneous scenarios (where agents compete with other agents who have the same personality type as its), as well as in heterogeneous scenarios (where agents compete with other agents who have personalities different from its). Other study scenarios could also be implemented to benefit from this approach to allow the observation of behavioral aspects and how they can affect performance in performing tasks in different contexts, such as in an organizational environment.

\subsection{Framework}

With the application of MBTI in conjunction with a multiagent system architecture based on the BDI framework, it then proposed a series of procedures to make it possible to represent psychological types in agent modeling. First, a method called perception function is developed, and with it, the agent can sense the environment in which it finds itself and interprets the data that its sensor will be able to capture. Thus, the agent can use this input data, called raw sensor inputs, and then sensitize the perception function [13].

With this approach, the researchers developed a scenario in which the agents had the task of collecting items that represented food. At the beginning of each cycle, an amount of food is distributed into the environment. With that, the task of the agents, modeled with MBTI, consisted basically of collecting the food and place them in piles distributed in certain places of the environment.
In this proposed scenario, the perception function receives the distance between the agent and the closest object (food) as input to its sensor. Then, the framework proposes that the agent can also interpret the input sensor in conjunction with its personality type, that is, according to the authors "a set of values containing the agent's personality type preferences". In this part, the second dichotomy (S-N) is the main one responsible for defining what will be represented in the agent regarding its behavioral characteristic. They explain, for example, that $\mathrm{S}$ type agents (Sensing) tend to interpret the input sensor with a focus on the short-term and more concrete objectives. Agents with personality type N (iNtuition) will focus on the "big picture" abstracting gains that may come in the longer term. These definitions will compose the beliefs of the agent.

Thus, the framework then suggests that as a next step, the agent will evaluate its beliefs in order to define its desires. The agent takes into account - in addition to the interpretation of its beliefs - also its internal state, its set of short and long-term objectives, and its personality type represented by dichotomy (T-F).According to the agent's behavioral preference, this dichotomy also has the critical function of defining desires, which is the best decision to be taken. In this case, the authors explain that $\mathrm{F}$ type agents (Feeling) may consider what other agents around them may wish to do, predicting that other agents closer to their initial targets may have the desire to go to these same goals they have had wanted first, thus placing the priorities of others ahead of its own. On the other hand, a $\mathrm{T}$ type agent (Thinking) will focus only on its own priorities, ignoring goals that other agents around it may have. With the definition of their desires, the framework then suggests the desires can be converted into intentions. Based on the output of the T-F dichotomy, the decision-making process is complemented.

In this way, with the definition of intentions, the agent will have the ability to define a plan to be followed, taking into account their behavioral preferences. The dichotomy (J-P) has a fundamental role in supporting the agents' decision-making process, determining their level of commitment to their current intention. Type $\mathbf{J}$ agents are more likely to be highly committed to fulfilling a previously established plan so that, regardless of new events that may arise after the initial plan has been defined, it follows what has been committed to doing. On the other hand, type $\mathrm{P}$ agents will constantly reevaluate the commitment they made, evaluating new events that may arise and eventually changing the commitments previously established with a view to greater gains with these new decisions made. Thus, when reassessing the options, the agent will have a set of possible actions to be performed, which, according to their behavioral preference, can be put into practice [13].

The dichotomy (E-I) also plays an important role in all steps of the process, being responsible for defining how much energy each agent will have. In [13] it is explained that type E (Extraversion) agents like to interact with other agents around them, receiving more energy as they get more interaction with 
them and making them seek to interact, help and collaborate with other agents. Type I (Introversion) agents, on the other hand, prefer to act alone, seeking to achieve their objectives in a solitary way. Thus, it is noted that each of the dichotomies has an important impact on the agents' behavior and decisionmaking process, and Table 3 (adapted from [32]) summarizes their influence in each phase of the BDI process.

The framework proposed by [13] seeks to evaluate how agents, influenced by their behavioral preferences derived from the psychological types described in MBTI, act in relation to the achievement of a certain task, analyzing the performance of each agent in different scenarios simulated. As shown in Figure 2, the authors demonstrate that even performing a simple task, agents with different personalities can follow different paths in achieving these same tasks, consequently making the resulting performance also impacted by these behavioral differences.

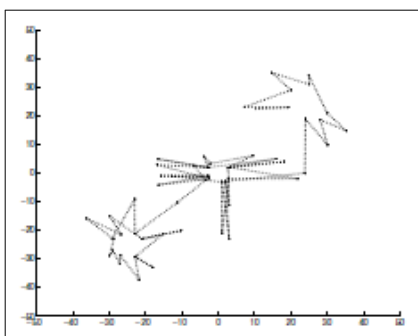

(a) $\mathrm{SJ}$

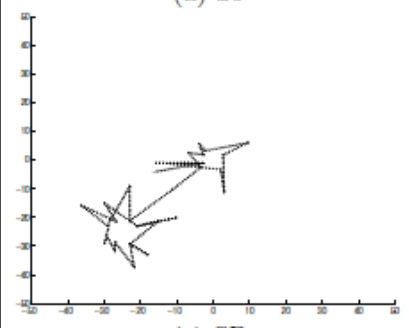

(c) SP

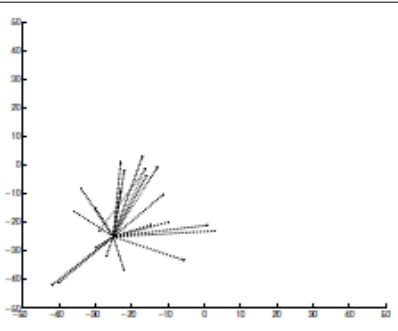

(b) NJ

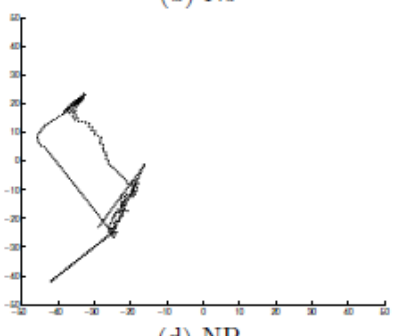

(d) NP
Figure 2. Typical paths taken by each agent personality. Different path shapes and lenghts reflect different decisions about where to go. [13]

\subsection{Result Analysis}

In [13] [32] [33], the authors sought through the proposed framework to observe how the behavior of agents modeled with the personalities types of MBTI could affect their performance in carrying out a simple task by developing several experiments in scenarios containing multiple agents. The results obtained demonstrated that agents modeled with different personalities, derived from the BDI model, have different performances in executing the same tasks. They conclude that these personalities can indeed directly influence the choices made by agents, thus affecting their consequent performance. In Figure 3 it is possible to observe the results measured regarding the total of food particles collected and the number of moves taken by the agents. It also can be perceived that each personality type has distinct performance in both analyzed aspects.

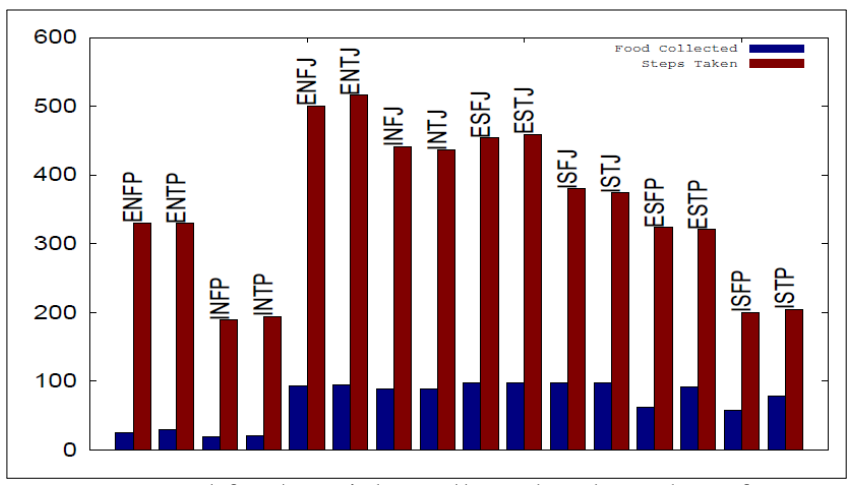

Figure 3. Total food particles collected and number of moves taken. [32]

It is also analyzed in an integrated way the efficiency of the agents in the performance of the task, calculating this metric as the amount of food collected divided by the number of steps taken as demonstrated in Figure 4.

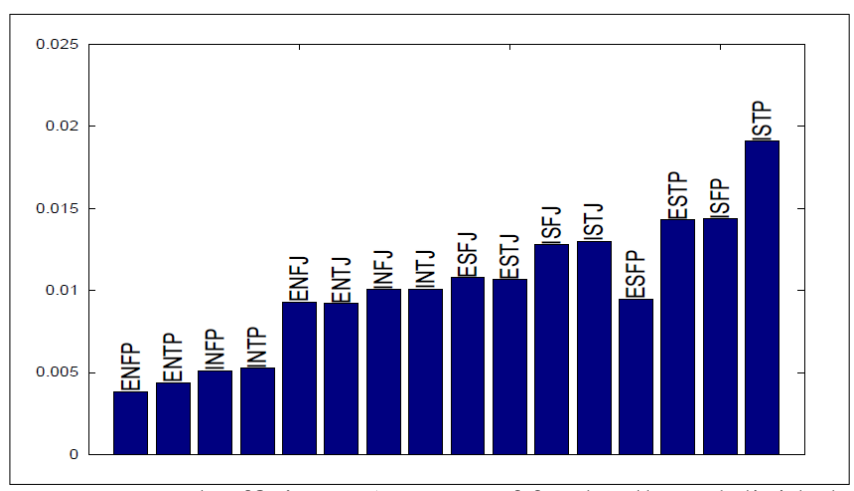

Figure 4. Task efficiency (amount of food collected divided by time). [32]

As mentioned by the authors, it is possible to observe that iNtuitive agents are less efficient than the Sensing agents and that the ${ }^{*} \mathrm{~N} * \mathrm{P}$ agents are the least efficient. This metric suggests that the different behaviors performed by agents can significantly impact their overall performance, influencing their decision-making according to the psychological type associated with each one.

Despite this, the proposed food collection scenario can lead to conclusions that do not necessarily apply to other contexts, such as situations involving more complex behaviors, so it is recommended that new avenues be explored in future research.

\section{A preliminary discussion on using MBTI agents for team formation}

In [13], the researchers took an important step in extending the BDI with capabilities for modeling agents following the psychological types described in MBTI and provided a valuable tool for other issues to be explored from the proposed 
Table 3. MBTI influences in BDI process [32]

\begin{tabular}{lcccc}
\hline & E-I & S-N & T-F & J-P \\
\hline sense environment and update beliefs & $\mathrm{X}$ & $\mathrm{X}$ & & \\
\hline update desires and intentions & $\mathrm{X}$ & & $\mathrm{X}$ & \\
\hline update plan and select actions & $\mathrm{X}$ & & & $\mathrm{X}$
\end{tabular}

framework. A relevant topic in this sense then would be to study how the suggested framework could assist in observing and analyzing human behavior in an organizational context considering not only an individual but also the impact of a group of people organized as a team performing a common task the group.

The problem of competitiveness in organizations and the study of the influence represented by the human factor has been thematic of several researchers over the years who emphasize that the competitive advantage comes directly from the knowledge of their employees [34]. Enable companies to have an environment conducive to knowledge sharing among employees can be a fundamental factor in transforming personal knowledge into a strategic differential in the market. In [35] can be seen that "the evidence of a vast array of research concerning teamwork is conclusive: teams are capable of outstanding performance and are the primary unit of performance for increasing numbers of organizations", and thus advancing the studies of the aspects related to the building of these work teams could have an influence on higher performance in organizations and may result in a significant impact on their results. A high-performance team is one that successfully develops all its potential with concerning stakeholders with a shared purpose, where individuals' interpersonal skills play an essential role as one of the leading facilitators in this process [36].

Using MBTI as a basis for modeling agents in a multiagent system could help analyze how the agents' attitudes and decisions could affect the performance of a work team. With that, the framework suggested in [13] could be extended to a context of analysis of work teams, observing how teams formed with multiple compositions of personalities could act together to achieve an objective that is common to the team (and not only to the individual).

To better present, the potential use of the demonstrated framework, Figure 5 shows an example of a possible scenario considering two teams, each of them composed of four agents with distinct personalities. Each could be modeled with personality types derived from MBTI, thus simulating agents' behaviors and decisions based on the framework proposed by Salvit and Sklar. In this way, it would be possible to analyze whether different personalities could impact the team's overall performance, analyzing how particularities present in certain personality types could influence the decisions made.

The adaptation of the scenarios used by the authors is also another critical aspect that could be explored in further studies. The scenarios developed were based on performing

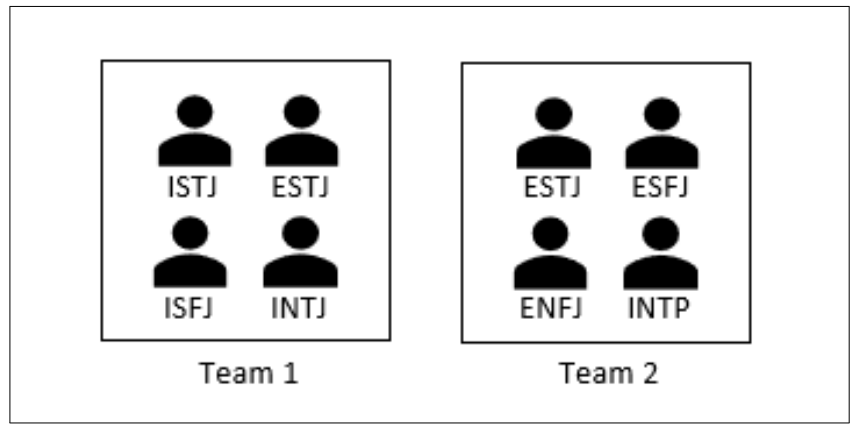

Figure 5. Heterogeneous Teams with four agents

simple tasks in which agents collect food items around the environment to stack them in specific fixed locations. For the performance analysis of work teams, other scenarios could then be developed aiming at more similar tasks to those found in organizational work contexts. As an example, a scenario in which agents represent buyers and sellers could be explored to represent a reality closer to organizational environments. This approach, already used in other studies [37] [38] [39], would help to represent more complex interactions involving situations such as negotiation, conflicts, cooperation, teamwork, among others, often found in corporate context.

As mentioned in Section 1, the goal of this paper is to show how MBTI has already been used in MAS and to briefly discuss some possible adaptations needed to be used in more complex simulations involving the formation of high-performance teams. More detailed studies, experiments, and simulations involving the proposed adaptations should be carried out to expand the scope, thus providing outstanding academic contributions.

\section{Conclusions and Future Work}

The paper presents a review of previous studies that serve as an important basis to evolve in researching the influence of psychological aspects on human behavior. It seeks to analyze how the MBTI instrument, proposed by Isabel Myers and Katherine Briggs, can represent some of these psychological characteristics of the human being in artificial agents developed using computational resources.

Through the use of multi-agent-based systems, it is sought to comprehend better how different psychological types can be represented in the agents seeking to analyze the influence of these psychological characteristics in its decision-making process. To this end, studies that expanded the ability to represent these factors in multiagent systems were analyzed, which 
through simulations and experiments could demonstrate different behaviors by agents, modeled with different personalities, and performing common tasks. Then, new studies can be developed and expand knowledge of the impact of the human factor in different situations. In this context, it is clear that BDI can provide an important advance in the simulation of human behavior by agents, and the study conducted by Jordan Salvit and Elizabeth Sklar stands out, demonstrating how it is possible to expand BDI to represent psychological types derived from MBTI as well.

This paper also sought to analyze a potential use of the studied framework to support the development of new models to evolve in the understanding of aspects related to the behavior of individuals in a work context, analyzing possible adaptations that can be done to understand the essential characteristics to build high-performance teams in companies.

As the next steps, it is expected to investigate and expand the use of the framework applied to work teams, enabling experiments and simulations in scenarios closer to organizational reality. With this, new models can be developed to analyze the behavior of teams of agents observing the influence of their different personalities in the actions they will perform in the environment, considering scenarios closer to those found in companies, and representing more realistic situations. This approach may represent an important advance in understanding factors related to human behavior in a work context, allowing more effective actions to be developed aiming, for example, to mitigate problems related to individuals' behavioral differences.

\section{Author contributions}

Luiz Fernando Braz contributed with the research, framework adaptation, experiments, paper writing. Jaime Simão Sichman (advisor) contributed with guidance for the research, development, experimentation, paper review, and improvement.

\section{References}

[1] BRAZ, L. F.; SICHMAN, J. S. Um estudo do myers-briggs type indicator (mbti) para modelagem de sistemas multiagentes no apoio a processos de recrutamento e seleção nas empresas. In: Anais do XIV Workshop-Escola de SistemasAgentes, seus Ambientes e aplicações de Agentes, seus Ambientes e aplicações. [S.1.]: Zenodo, 2020. p. 250-255.

[2] ZANELLI, J. C.; BORGES-ANDRADE, J. E.; BASTOS, A. V. B. Psicologia, Organizações e Trabalho no Brasil-2. [S.1.]: AMGH Editora, 2014.

[3] IBARRA, M. F. Psicotecnia. historia de un encuentro entre la psicología y la técnica. Revista Internacional sobre Subjetividad, Política y Arte, v. 11, n. 2, p. 71-85, 2015.

[4] SPECTOR, P. E. Psicologia nas organizações. [S.1.]: Saraiva Educação SA, 2009.
[5] ESCHLEMAN, K. J.; WRIGHT, C. W. (mis) steps for attracting high resilience workers. Industrial and Organizational Psychology, Cambridge University Press, v. 9, n. 2, p. 429-435, 2016.

[6] MYERS, I. B. et al. MBTI manual: A guide to the development and use of the Myers-Briggs Type Indicator. [S.1.]: Consulting Psychologists Press Palo Alto, CA, 1998. v. 3.

[7] MUPINGA, D. M.; NORA, R. T.; YAW, D. C. The learning styles, expectations, and needs of online students. College teaching, Taylor \& Francis, v. 54, n. 1, p. 185-189, 2006.

[8] BROWN, F. W.; REILLY, M. D. The myers-briggs type indicator and transformational leadership. Journal of Management Development, Emerald Group Publishing Limited, 2009.

[9] LUO, C. The application of mbti theory in hiring sales staffs. In: SPRINGER. The 19th International Conference on Industrial Engineering and Engineering Management. [S.1.], 2013. p. 703-709.

[10] ALVARES, L. O.; SICHMAN, J. S. Introduçao aos sistemas multiagentes. In: XVII Congresso da SBC-Anais JAI'97. [S.1.: s.n.], 1997.

[11] SYCARA, K. P. Multiagent systems. AI magazine, v. 19, n. 2, p. 79-79, 1998.

[12] MYERS, I. B. Introduction to type: A guide to understanding your results on the Myers-Briggs Type Indicator. Mountain View, CA: CPP. [S.1.]: Inc, 1998.

[13] SALVIT, J.; SKLAR, E. Toward a myers-briggs type indicator model of agent behavior in multiagent teams. In: SPRINGER. International Workshop on Multi-Agent Systems and Agent-Based Simulation. [S.1.], 2010. p. 28-43.

[14] FURNHAM, A.; STRINGFIELD, P. Personality and work performance: Myers-briggs type indicator correlates of managerial performance in two cultures. Personality and individual Differences, Elsevier, v. 14, n. 1, p. 145-153, 1993.

[15] COOPER, S. E.; MILLER, J. A. Mbti learning style-teaching style discongruencies. Educational and Psychological Measurement, Sage Publications Sage CA: Thousand Oaks, CA, v. 51, n. 3, p. 699-706, 1991.

[16] CHEN, S.-J.; LIN, L. Modeling team member characteristics for the formation of a multifunctional team in concurrent engineering. IEEE Transactions on Engineering Management, IEEE, v. 51, n. 2, p. 111-124, 2004.

[17] FURNHAM, A. Myers-briggs type indicator (mbti). In: _. Encyclopedia of Personality and Individual Differences. Cham: Springer International Publishing, 2020. p. 3059-3062. Disponível em: $\langle$ https://doi.org/10.1007/978-3-319-24612-3_50〉. 
[18] COE, C. K. The mbti: Potential uses and misuses in personnel administration. Public Personnel Management, SAGE Publications Sage CA: Los Angeles, CA, v. 21, n. 4, p. 511-522, 1992.

[19] BOYLE, G. J. Myers-briggs type indicator (mbti): some psychometric limitations. Australian Psychologist, Wiley Online Library, v. 30, n. 1, p. 71-74, 1995.

[20] PITTENGER, D. J. Measuring the mbti... and coming up short. Journal of Career Planning and Employment, v. 54, n. 1, p. 48-52, 1993.

[21] MARTINEZ-MIRANDA, J.; ALDEA, A. Emotions in human and artificial intelligence. Computers in Human Behavior, Elsevier, v. 21, n. 2, p. 323-341, 2005.

[22] CALEGARI, R. et al. Logic-based technologies for intelligent systems: State of the art and perspectives. Information, Multidisciplinary Digital Publishing Institute, v. 11, n. 3, p. 167, 2020.

[23] CONTE, R.; GILBERT, N.; SICHMAN, J. S. MAS and social simulation: A suitable commitment. In: SPRINGER. International Workshop on Multi-Agent Systems and Agent-Based Simulation. [S.1.], 1998. p. 1-9.

[24] LUKE, S. et al. Mason: A multiagent simulation environment. Simulation, Sage Publications Sage CA: Thousand Oaks, CA, v. 81, n. 7, p. 517-527, 2005.

[25] NORLING, E.; SONENBERG, L. Creating interactive characters with bdi agents. 022004.

[26] BRATMAN, M. E.; ISRAEL, D. J.; POLLACK, M. E. Plans and resource-bounded practical reasoning. Computational intelligence, Wiley Online Library, v. 4, n. 3, p. 349-355, 1988.

[27] PADGHAM, L.; LAMBRIX, P. Agent capabilities: Extending bdi theory. In: AAAI/IAAI. [S.1.: s.n.], 2000. p. 68-73.

[28] RAO, A. S.; GEORGEFF, M. P. et al. Bdi agents: from theory to practice. In: Icmas. [S.1.: s.n.], 1995. v. 95, p. 312-319.

[29] DIENER, E.; LUCAS, R. E. Personality traits. In: General psychology: Required reading. [S.1.: s.n.], 2019. p. 278.
[30] PANKSEPP, J. Affective Neuroscience, the Foundations of Human and Animal Emotions. Oxford University Press, USA, 1998. Disponível em: 〈http://gen.lib.rus.ec/book/index. php?md5=395084975cf51beb09043ea2451c31f7 $\rangle$.

[31] PEREIRA, D. et al. Towards an architecture for emotional bdi agents. In: IEEE. 2005 portuguese conference on artificial intelligence. [S.1.], 2005. p. 40-46.

[32] SALVIT, J.; SKLAR, E. Modulating agent behavior using human personality type. In: Proceedings of the Workshop on Human-Agent Interaction Design and Models (HAIDM) at Autonomous Agents and MultiAgent Systems (AAMAS). [S.1.: s.n.], 2012. p. 145-160.

[33] SALVIT, J. Extending BDI with Agent Personality Type. Tese (Doutorado) - The City University of New York, 2012. [34] MENEGON, L.; CASADO, T. O contrato psicológico como ferramenta para a gestão de pessoas. Revista De Administração, v. 41, n. 2, p. 125-135, 6 2006. Disponível em: 〈http://www.periodicos.usp.br/rausp/article/view/44393 [35] CASTKA, P. et al. Factors affecting successful implementation of high performance teams. Team Performance Management: An International Journal, MCB UP Ltd, 2001.

[36] SHARP, J. M. et al. Continuous organisational learning through the development of high performance teams. In:

ICSTM. [S.1.: s.n.], 2000.

[37] TRAN, T.; COHEN, R. A learning algorithm for buying and selling agents in electronic marketplaces. In: SPRINGER. Conference of the Canadian Society for Computational Studies of Intelligence. [S.1.], 2002. p. 31-43.

[38] DELOACH, S. A. Modeling organizational rules in the multi-agent systems engineering methodology. In: SPRINGER. Conference of the Canadian Society for Computational Studies of Intelligence. [S.1.], 2002. p. 1-15.

[39] XU, H.; SHATZ, S. M. An agent-based petri net model with application to seller/buyer design in electronic commerce. In: IEEE. Proceedings 5th International Symposium on Autonomous Decentralized Systems. [S.1.], 2001. p. 11-18. 